\title{
A novel technique for adjusting traction direction during colorectal endoscopic submucosal dissection using S-O clip
}

A 67-year-old man had an elevated lesion with central shallow depression, approximately $20 \mathrm{~mm}$ in size across a colonic fold in the splenic flexure ( $\mathbf{F i g . 1}$ ). Magnified chromoendoscopy revealed a noninvasive pit pattern (type $V_{1}$ mild in Kudo's classification). The patient opted for endoscopic submucosal dissection (ESD) ( $\triangleright$ Video 1).

Mucosal incision was followed by submucosal dissection of the distal side using a DualKnife J (KD-655Q; Olympus Medical, Tokyo, Japan) and insulated-tip knife nano (KD-612U; Olympus Medical). Submucosal dissection was meticulously performed because of poor submucosal lifting despite the use of sodium hyaluronate ( $\triangleright$ Fig. 2 ).

To secure the submucosal space, an endoclip with a ring-loaded spring (S-O clip, TC1H05; Zeon Medical, Tokyo, Japan) was applied to the distal edge of the specimen and anchored to the opposite bowel wall with another endoclip. This resulted in sufficient tissue traction at the distal edge, and the submucosal space was well exposed, allowing efficient and safe submucosal dissection ( $\vee$ Fig.3a). The submucosal space became poorly visualized again with insufficient traction when the lesion retracted proximally, obscured by a colonic fold. We removed the second endoclip by pulling the endoclip cover up using a clip device, and anchored the ring to the opposite wall proximally ( $\vee$ Fig. $\mathbf{3}$ b), leaving the lesion well stretched with better exposure of the submucosal layer on the proximal side, enabling successful en bloc resection ( $\mathbf{F i g . 4}$ ). The resected specimen showed well-differentiated tubular adenocarcinoma histologically, with invasion limited to the superficial submucosa $(50 \mu \mathrm{m}$ from muscularis mucosa), measuring $15 \times 14 \mathrm{~mm}$ in size, with free margin, and without lymphovascular invasion.

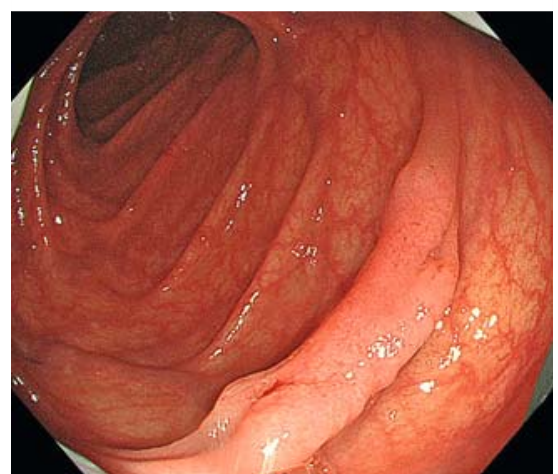

- Fig. 1 An elevated lesion with central shallow depression in the splenic flexure of the transverse colon.

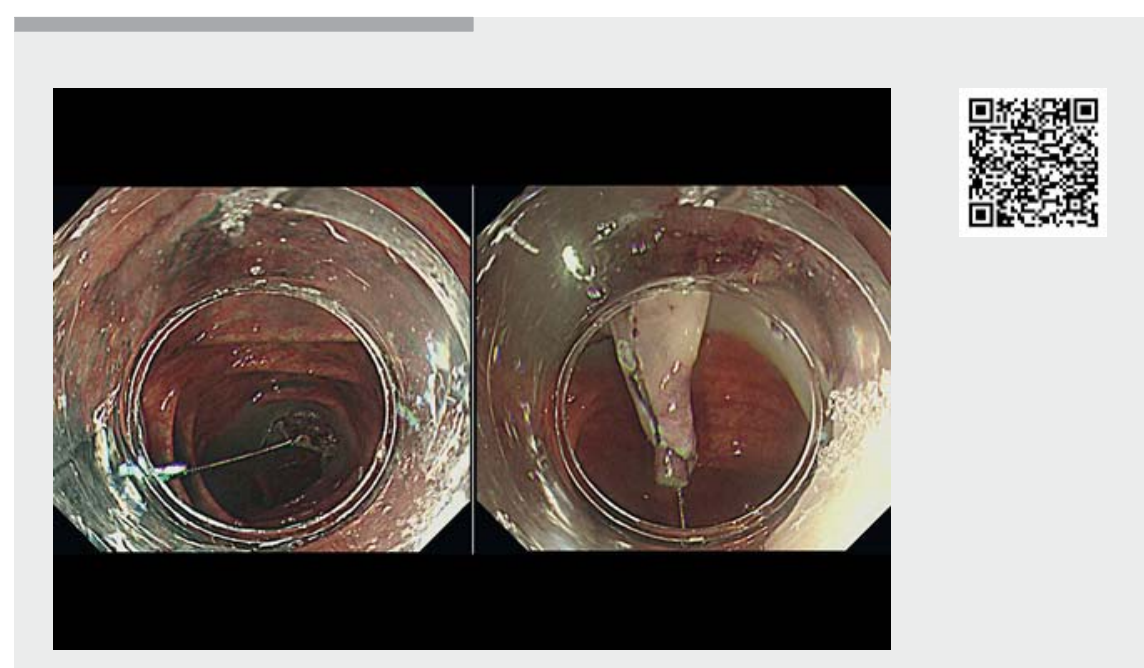

Video 1 Colorectal endoscopic submucosal dissection was performed for an elevated lesion with central shallow depression across a colonic fold. The traction direction was adjusted from distally to proximally during the procedure using the S-O clip.

The S-O clip is a useful traction device in colorectal ESD [1,2]. In this case, the clips were advantageous as the traction direction could be adjusted from distally to proximally, even during ESD, by removing and re-anchoring the loaded ring.

Endoscopy_UCTN_Code_TTT_1AQ_2AD

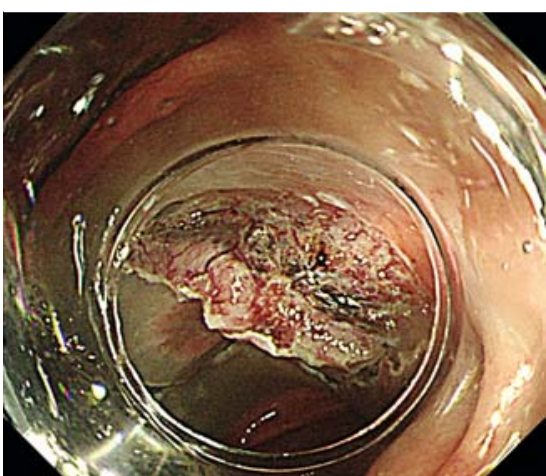

Fig. 2 Submucosal lifting of the center of the lesion was poor owing to submucosal fibrosis. 

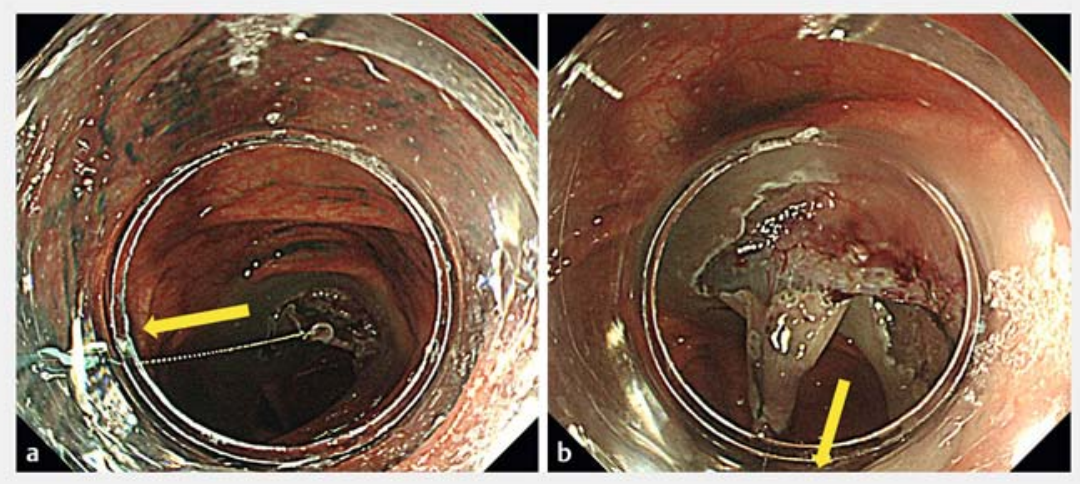

- Fig. 3 Use of the S-O clip for traction. a The S-O clip was applied to the distal edge of the specimen and anchored to the other side of the lumen with another endoclip (arrow). $\mathbf{b}$ When visualization deteriorated due to reduced traction as the procedure progressed, the second endoclip was removed and the S-O clip was re-anchored to the opposite bowel wall proximally (arrow).

\section{Competing interests}

The authors declare that they have no conflict of interest.

The authors

Yutaka Okagawa ${ }^{1,2}$, Seiichiro Abe ${ }^{1}$, Hiroyuki Takamaru' ${ }^{1}$, Masau Sekiguchi ${ }^{1,3}$, Masayoshi Yamada', Taku Sakamoto ${ }^{1}$, Yutaka Saito ${ }^{1}$

1 Endoscopy Division, National Cancer Center Hospital, Tokyo, Japan

2 Department of Gastroenterology, Tonan Hospital, Sapporo, Japan

3 Cancer Screening Center, National Cancer Center Hospital, Tokyo, Japan

Corresponding author

\section{Seiichiro Abe, MD, PhD}

Endoscopy Division, National Cancer Center Hospital, 5-1-1 Tsukiji, Chuo-ku, Tokyo

104-0045, Japan

Fax: +81-3-35423815

seabe@ncc.go.jp

\section{References}

[1] Ritsuno H, Sakamoto N, Osada T et al. Prospective clinical trial of traction device-assisted endoscopic submucosal dissection of large superficial colorectal tumors using the S-O clip. Surg Endosc 2014; 28: 3143-3149

[2] Okamoto Y, Oka S, Tanaka S et al. Clinical usefulness of the $\mathrm{S}-\mathrm{O}$ clip during colorectal endoscopic submucosal dissection in difficult-to-access submucosal layer. Endosc Int Open 2020; 8: E437-E444

\section{Bibliography}

Endoscopy 2021; 53: E177-E178

DOI 10.1055/a-1216-1167

ISSN 0013-726X

published online 20.8.2020

(C) 2020. Thieme. All rights reserved. Georg Thieme Verlag KG, Rüdigerstraße 14, 70469 Stuttgart, Germany

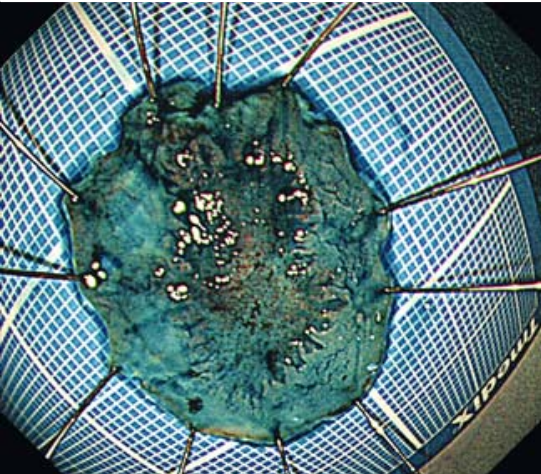

Fig. 4 En bloc resection was achieved without complications. The resected specimen showed Type 0-Ila + IIc (laterally spreading tumor, nongranular type), well-differentiated tubular adenocarcinoma histologically, with the depth of invasion limited to the superficial submucosa (50 $\mu \mathrm{m}$ from muscularis mucosa), measuring $15 \times 14 \mathrm{~mm}$ in size, with free margin, and without lymphovascular invasion.

\section{ENDOSCOPY E-VIDEOS}

https:/|eref.thieme.de/e-videos

口回 Endoscopy E-Videos is a free 然的 access online section, reporting on interesting cases and new techniques in gastroenterological endoscopy. All papers include a high quality video and all contributions are freely accessible online.

This section has its own submission website at

https://mc.manuscriptcentral.com/e-videos 